\title{
Densidade e resistência do solo à penetração de raízes em agroecossistemas no semiárido brasileiro
}

\section{Density and soil resistance to root penetration in agroecosystems in the Brazilian semiarid}

\author{
Gabriela Carvalho Maia de Queiroz ${ }^{1}$; Francisco Wellington Andrade Silva ${ }^{2}$; Jeane Cruz Portela ${ }^{3}$; \\ Valéria Nayara Silva de Oliveira ${ }^{4}$; Mikael Varão dos Santos ${ }^{5}$
}

${ }^{1}$ Discente do Curso de Engenharia Agrícola e Ambiental, Universidade Federal Rural do Semi-árido, Mossoró, Rio Grande do Norte, gabrielac99@outlook.com; ${ }^{2}$ Engenheiro Agrônomo, Universidade Federal Rural do Semi-árido, Mossoró, Rio Grande do Norte, fwellingtonas@ gmail.com; ${ }^{3}$ Docente do Centro de Ciências Agrárias, Departamento de Ciências Agronômicas e Florestais, Universidade Federal Rural do Semi-árido, Mossoró, Rio Grande do Norte, jeaneportela@ ufersa.edu.br; ${ }^{4}$ Mestranda do Programa de Pós-Graduação em Ambiente, Tecnologia e Sociedade, Universidade Federal Rural do Semi-árido, Mossoró, Rio Grande do Norte, valeria_naiara@ hotmail.com; ${ }^{5}$ Discente do Curso de Agronomia, Universidade Federal Rural do Semi-árido, Mossoró, Rio Grande do Norte, E-mail: mikkyvarao@gmail.com

\section{A R T I G O}

Recebido: $15 / 02 / 2019$

Aprovado: 26/09/2019

Palavras-chave:
Manejo Agroecológico
Caatinga
Estrutura do solo

Key words:

Agroecological

Management

Caatinga

Soil structure

\section{R E S U M O}

O manejo inadequado do solo modifica seus atributos, culminando na perda de sua qualidade produtiva. Diante do exposto, o objetivo com o presente trabalho foi avaliar os atributos de um Cambissolo em agroecossistemas, no Projeto de Assentamento Terra de Esperança, município de Governador Dix-Sept Rosado, no Rio Grande do Norte, por meio da técnica de estatística multivariada. Realizou-se a coleta de amostras de solo com estrutura deformada e indeformada, para realização de análises físicas e químicas, sendo as coletas feitas nas camadas de 0-5 e 5-10 $\mathrm{cm}$, em três repetições. Os atributos físicos avaliados foram: granulometria, densidade de partículas e densidade do solo, resistência do solo à penetração realizada a campo com penetrômetro, e porosidade total do solo. Os atributos químicos foram: condutividade elétrica, potencial hidrogeniônico em água, carbono orgânico total e macronutrientes: cálcio, magnésio, fósforo, potássio e o sódio, sendo posteriormente calculada a capacidade de troca de cátions, soma de bases e saturação por bases, e a percentagem de sódio trocável. As áreas de mata nativa e área agroecológica apresentaram similaridade entre si, sendo que os atributos estruturais resistência do solo à penetração e densidade do solo e os químicos carbono orgânico total, sódio, potássio, percentagem de sódio trocável e condutividade elétrica foram os mais sensíveis na distinção dos ambientes, em relação á área de plantio convencional de cultivos consorciados, indicando que os sistemas de usos do solo alteram seus atributos e que práticas agroecológicas propiciam melhorias e/ou manutenção destes.

\section{A B S T R A C T}

Inadequate soil management modifies its attributes, culminating in the loss of its product quality. Given the above, the objective of this study was to evaluate the attributes of a cambisol in Agroecosystems, in the Land of Hope Settlement project, in the municipality of Governador Dix-Sept Rosado, in Rio Grande do Norte, through the statistical technique Multivariate. Soil samples were collected with the deformed and undisturbed structure to perform physical and chemical analyses, and the collections were made in the layers of 0-5 and 5-10 cm, in three replications. The physical attributes evaluated were: granulometry, particle density and soil density, soil resistance to penetration carried out in a field with a penetrometer, and total soil porosity. The chemical attributes were: electrical conductivity, hydrogenionic potential in water, total organic carbon and macronutrients: calcium, magnesium, phosphorus, potassium and sodium, and subsequently the ability to exchange cations, a sum of bases and Base saturation, and the percentage of exchangeable sodium. The areas of native forest and agroecological area showed similarity among themselves, and the structural attributes soil resistance to penetration and bulk density and the chemical total organic carbon, sodium, potassium, percentage of exchangeable sodium and Electricalconductivity were the most sensitive in the distinction of the environments, in relation to the conventional planting area of intercropped crops, indicating that the soil use systems alter their attributes and that agroecological practices provide improvements and/or maintenance of these.

\section{Revista Verde}

ISSN 1981-8203

Pombal, Paraíba, Brasil v. 14, n.4, out.-dez, p.497-505, 2019

doi: $10.18378 /$ rvads.v14i4.6355 


\section{INTRODUÇÃO}

O solo desempenha e exibe interação sinérgica com todas as esferas componentes do ambiente, sendo agente ativo e passivo nessas inter-relações, atuando diretamente sobre o desenvolvimento das plantas na medida em que se constitui o meio físico para sustentar e prover o suprimento dos recursos abióticos essenciais, tais como nutrientes, gases, água e calor (CONCEIÇÃO et al., 2014).

A dinâmica da agricultura moderna em incorporar cada vez mais áreas ao processo produtivo, aliado ás práticas inadequadas de usos e manejo do solo e sem levar em consideração as particularidades locais, tem acelerado a perda da qualidade produtiva dos solos, modificando seus atributos físicos, químicos e biológicos (BERTOL et al., 2010).

Os usos e manejo do solo, sobretudo, os sistemas tradicionais de preparo intensivo, alteram os atributos físicos, e também os teores de matéria orgânica, os quais são os mais sensíveis às modificações. Essas alterações se tornam evidentes nos valores limitantes de densidade do solo, resistência à penetração de raízes, resultando no comprometimento do espaço poroso e da porosidade total (MARTINS et al., 2015).

Essa ideia é corroborada pelos estudos de Resende et al., (2012), ao avaliar os atributos físicos do solo sob diferentes usos, relata que os sistemas agropecuários alteraram consideravelmente os atributos estruturais do solo, e que os sistemas com preparo intensivo apresentaram redução significativa da qualidade estrutural, comprometendo principalmente a porosidade total, em relação à área de mata nativa. Nesse sentido, a avaliação dos impactos dos sistemas de manejo do solo, é realizada utilizando áreas de mata nativa preservada como referência, em função da mínima perturbação antrópica, sendo os sistemas com bases agroecológicas com utilização de práticas de suporte conservacionistas, com preparo mínimo do solo como também, diversidade de plantas, que favorecem à manutenção da qualidade estrutural do solo (PORTUGAL et al., 2010).

Neste contexto, é essencial a caracterização dos atributos do solo nos agroecossistemas, por meio dos diferentes usos, buscando avaliar qual sistema é compatível com modelos de produção conservacionistas, e consequentemente, delinear o planejamento de práticas sustentáveis e condizentes com a capacidade produtiva do solo, que garantam a realização das atividades agrícolas de forma a gerar o menor impacto ambiental, primando pela preservação dos espaços naturais, estimulando a reciclagem de nutrientes e conservando a biodiversidade, permitindo que o solo desempenhe adequadamente as suas funções (FREITAS et al., 2017; ARRUDA et al., 2018).

Diante do exposto, o objetivo com o presente trabalho foi avaliar os atributos físicos e químicos do solo sob diferentes usos, para detectar quais atributos foram mais sensíveis na distinção dos ambientes, por meio da técnica de estatística multivariada, no Projeto de Assentamento Terra de Esperança, em Governador Dix-Sept Rosado, Rio Grande do Norte.

\section{MATERIAL E MÉTODOS}

A pesquisa foi realizada no Projeto de Assentamento Terra da Esperança, situado no município de Governador
Dix-Sept Rosado, no estado do Rio Grande do Norte, inserido na mesorregião Oeste Potiguar, microrregião da Chapada do Apodi e na região semiárida do Brasil. O município de Governador Dix-Sept Rosado apresenta classificação climática segundo Köppen, semiárido quente e seco, tipo BSwh, com precipitação pluvial anual média de $712 \mathrm{~mm}$, durante os meses de fevereiro a maio (ALVARES et al., (2013). A vegetação predominante é a Caatinga Hiperxerófila, com espécies de hábito caducifólio.

O Projeto de Assentamento Terra de Esperança está localizado na porção sudeste do município de Governador Dix-Sept Rosado, nas coordenadas geográficas $5^{\circ} 30^{\prime} 12,19^{\prime}$ ' $\mathrm{S}$ e $37^{\circ} 27^{\prime} 26,66^{\prime}$ 'O. Possui uma área total de 6.297 hectares, constituída de uma vila com 30 lotes e 113 famílias, cada uma com 30 hectares, que foram instaladas desde o ano de 1998 com a posse das terras, concedida pelo Instituto Nacional de Colonização e Reforma Agrária (INCRA). Nesse estudo, foram selecionados três agroecossistemas: Área de mata nativa $(\mathrm{MN})$, utilizada como referência; área convencional em cultivos consorciados (PC) e área agroecológica $(\mathrm{Ag})$, sendo o solo das áreas avaliadas classificado como Cambissolo Háplico eutrófico (SANTOS et al., (2013), conforme Tabela1.

Para a caracterização dos ambientes, realizou-se a coleta de amostras de solo com estrutura deformada e indeformada, para realização de análises físicas e químicas, conforme Teixeira et al., (2017), sendo as amostragens realizadas nas camadas de 0-5 e 5-10 cm, com cinco amostras compostas, oriundas de 15 subamostras, retiradas com auxílio do trado tipo holandês, para cada área e camadas supracitadas, sendo realizadas em triplicata no laboratório. Estas amostras foram identificadas, acondicionadas em sacos plásticos e encaminhadas ao Laboratório de Análise de Solo, Água e Planta do Departamento de Ciências Agronômicas e Florestais da Universidade Federal Rural do Semi-árido (LASAP/DCAF/UFERSA), Campus de Mossoró-RN.

Posteriormente, as amostras foram secas ao ar, destorroadas e passadas em peneiras com malha de $2 \mathrm{~mm}$ de diâmetro, para obtenção da terra fina seca ao ar (TFSA), sendo submetidas às análises físicas de granulometria e densidade de partículas. A granulometria foi determinada pelo método da pipeta. A análise de densidade de partículas foi realizada pelo método do balão volumétrico (TEIXEIRA et al., 2017).

A resistência mecânica do solo à penetração de raízes (RP) foi determinada nas condições de campo, utilizando um penetrômetro de impacto da VDO®, sendo realizadas 30 leituras em cada camada $(0-5$ e $5-10-\mathrm{cm})$ e os resultados expressos em MPa, conforme descrito por Forsythe (1975). Na mesma ocasião, realizou-se coleta de amostras deformadas nas respectivas camadas para realização da umidade gravimétrica, conforme descrito por Forsythe (1975), e os resultados foram expressos em $\mathrm{g} \mathrm{g}^{-1}$. (Quanto à densidade do solo, coletou-se amostras indeformadas utilizando equipamento tipo Uhland, nas camadas de 0-5 e 5-10-cm) em anéis com dimensões de $0,05 \mathrm{~m}$ de altura e $0,05 \mathrm{~m}$ de diâmetro, sendo coletadas 10 amostras nas respectivas camadas. A densidade do solo foi determinada pelo do anel volumétrico descrito por Forsythe (1975), com volume conhecido, e tomando-se a média dos valores obtidos, representada pelo quociente da massa das partículas sólidas do solo pelo volume total do solo, e expressa em $\mathrm{kg} \mathrm{dm}^{-3}$. A 
porosidade total do solo calculada (PTcalc) foi obtida de forma indireta pela equação: Ptcalc $=1-(\mathrm{Ds} / \mathrm{Dp}) \times 100$
Em que: Ptcalc $=$ Porosidade total calculada, em $\% ;$ Ds $=$ densidade do solo, em $\mathrm{kg} \mathrm{m}^{-3}$; eDp = densidade das partículas, em $\mathrm{kg} \mathrm{m}^{-3}$.

Tabela 1. Áreas estudadas, coordenadas geográficas e histórico de uso, no Projeto de Assentamento Terra de Esperança, Município de Governador Dix-Sept Rosado, Rio Grande do Norte.

$\begin{array}{ccc}\begin{array}{c}\text { Áreas } \\ \text { estudadas }\end{array} & \begin{array}{c}\text { Coordenadas } \\ \text { geográficas }\end{array} & \text { Histórico de uso }\end{array}$

$5^{\circ} 31^{\prime} 10^{\prime \prime} \mathrm{S}$
$37^{\circ} 27^{\prime} 12^{\prime \prime} \mathrm{W}$

Área Convencional em Cultivos Consorciados (PC) $5^{\circ} 300^{\prime} 39,1^{\prime \prime} \mathrm{S}$ $37^{\circ} 27^{\prime} 48,6^{\prime}, \mathrm{W}$

$5^{\circ} 30^{\prime} 23,302 ” \mathrm{~S}$ $37^{\circ} 27^{\prime} 5,877^{\prime} \mathrm{W}$

Esta área apresenta como vegetação predominante a Caatinga hiperxerófila, com espécies arbustivas e rasteiras. Constitui uma área sob reserva ambiental preservada, sendo usada como referência quanto aos atributos do solo. Anteriormente, foi utilizada pelos assentados para o extrativismo vegetal de lenha apenas para cerca de outras áreas do assentamento, destaca-se também na produção de mel.

Ambiente cultivado com milho (Zea mays) e feijão-de-corda (Vigna unguiculata L.) consociados. O preparo do solo convencional constitui em uma aração e duas gradagens, contudo, não há uso de fertilizantes minerais nem uso de queimadas na área por parte dos assentados, sendo usada dessa forma desde 2005. A agricultura nessas terras é realizada sob a forma de sequeiro, aproveitando a estação chuvosa.

A área foi definida e implantada no ano de 2005, por meio de iniciativa dos assentados, sendo voltada para a produção de alimentos (frutíferas) e (forrageiras) para atender as necessidades das famílias e dos animais. Este ambiente é utilizado de forma agroecológica, com histórico de adoção de práticas voltadas a conservação do solo e da água, tais como: Construção de barreiras físicas, como camalhões, para reduzir o escoamento superficial da água e consequentemente, a erosão laminar, sendo também realizada a introdução de novas espécies vegetais (enriquecimento da Caatinga) e a incorporação de resíduos de plantas. Essas práticas conjuntamente contribuem para a diversidade de plantas, e consequentemente, melhorias na estruturação do solo. Quanto ao manejo das espécies nativas, é realizada a prática de raleamento e rebaixamento da Caatinga, na época chuvosa e seca, sendo a vegetação nativa utilizada para alimentação dos animais.

As análises químicas determinadas foram: condutividade elétrica (CE), potêncial hidrogeniônico $(\mathrm{pH})$ em água, carbono orgânico total (COT) por digestão da matéria orgânica, e macronutrientes: cálcio trocável $\left(\mathrm{Ca}^{2+}\right)$,magnésio trocável $\left(\mathrm{Mg}^{2+}\right)$ com extrator cloreto de potássio, análise do fósforo $(\mathrm{P})$, e potássio $\left(\mathrm{K}^{+}\right)$, o sódio $\left(\mathrm{Na}^{+}\right)$com extrator Mehlich 1, conforme metodologia proposta por Teixeira et al., (2017). Posteriormente calculou-se a capacidade de troca de cátions (CTC), soma de bases (SB) e saturação por bases (V), e a percentagem de sódio trocável (PST), sendo interpretados conforme Manual de Recomendações para uso de corretivos e fertilizantes de Minas Gerais (RIBEIRO et al., 1999).

Os dados dos atributos físicos e químicos foram expressos por meio da média de quatro repetições, e submetidos à análise estatística multivariada como ferramenta principal utilizada para constatação dos atributos mais sensíveis na distinção dos solos ao uso agropecuário, utilizando o programa Software Statistica 7.0 (STATSOFT, 2004).

Para a matriz de correlação de Pearson $(p \leq 0,05)$, foi utilizado o valor de referência de 0,7 indicado na literatura, em função dos atributos selecionados apresentarem forte correlação entre si (NETO, 2015). A análise de agrupamento foi realizada com base no dendrograma vertical, adotando-se a distância euclidiana como medida de similaridade e o método de Ward para ligar os casos entre si. Para a análise fatorial foram extraídos fatores com autovalores acima de 1,00 , por meio de componentes principais, com eixos fatoriais rotacionados pelo método Varimax, adotando-se o valor de 0,65 para cargas fatoriais significativas (HAIR Jr. et al., 2009)

\section{RESULTADOS E DISCUSSÃO}

A Tabela 2 contém a matriz de correlação, que representa a relação de dependência entre as variáveis dos atributos do solo nas áreas em estudo, sob diferentes usos no Projeto de Assentamento Terra da Esperança-RN.

Correlações significativas foram encontradas entre os atributos do solo, com destaque para as correlações significativas encontradas entre as frações inorgânicas argila e areia grossa (Ag) e os atributos físicos Ptcal, Ds e Rp. As correlações altas e negativas entre as frações inorgânicas argila e areia $(-0,98)$ é resultado da textura do solo, uma vez que a mesma é um atributo intrínseco a solo e de difícil modificação, sendo oriundo da rocha. Os Cambissolos são solos rasos, podendo ou não apresentar intemperismo acentuado a depender do padrão climático, podendo ser classificados texturalmente em franco-arenosos, franco argiloarenosos ou com mais argila, apresentando geralmente teores uniformes de argila, com ligeiro decréscimo ou um pequeno incremento do horizonte A para o Bi (SANTOS et al., 2013). 
Gabriela Carvalho Maia de Queiroz et al.

Tabela 2. Matriz de correlação entre as variáveis dos atributos do solo nas áreas em estudo, no Projeto de Assentamento Terra da Esperança, Rio Grande do Norte

\begin{tabular}{|c|c|c|c|c|c|c|c|c|c|c|c|c|c|c|c|c|c|c|c|}
\hline & Argila & $\mathrm{AG}$ & A.F & Silte & Ds & $\mathrm{Dp}$ & Ptc & RP & $\mathrm{pH}$ & $\mathrm{CE}$ & $\mathrm{P}$ & $\mathrm{K}^{+}$ & $\mathrm{Na}^{+}$ & $\mathrm{Ca}^{2+}$ & $\mathrm{Mg}^{2+}$ & COT & CTC & SB & PST \\
\hline Argila & 1,00 & & & & & & & & & & & & & & & & & & \\
\hline $\mathrm{AG}$ & $-0,98$ & 1,00 & & & & & & & & & & & & & & & & & \\
\hline A.F & $-0,28$ & 0,14 & 1,00 & & & & & & & & & & & & & & & & \\
\hline Silte & 0,59 & $-0,52$ & $-0,86$ & 1,00 & & & & & & & & & & & & & & & \\
\hline Ds & 0,87 & $-0,92$ & 0,15 & 0,25 & 1,00 & & & & & & & & & & & & & & \\
\hline $\mathrm{Dp}$ & $-0,55$ & 0,58 & 0,51 & $-0,84$ & 0,87 & 1,00 & & & & & & & & & & & & & \\
\hline Ptc & $-0,85$ & 0,90 & 0,10 & $-0,53$ & $-0,92$ & 0,77 & 1,00 & & & & & & & & & & & & \\
\hline $\mathrm{RP}$ & 0,78 & $-0,69$ & $-0,57$ & 0,66 & 0,39 & $-0,33$ & $-0,40$ & 1,00 & & & & & & & & & & & \\
\hline $\mathrm{pH}$ & 0,64 & $-0,71$ & $-0,22$ & 0,69 & 0,61 & $-0,89$ & $-0,81$ & 0,39 & 1,00 & & & & & & & & & & \\
\hline $\mathrm{CE}$ & 0,53 & $-0,59$ & $-0,37$ & 0,78 & 0,43 & $-0,90$ & $-0,69$ & 0,41 & 0,97 & 1,00 & & & & & & & & & \\
\hline $\mathrm{P}$ & 0,83 & $-0,82$ & $-0,44$ & 0,77 & 0,71 & $-0,78$ & $-0,83$ & 0,55 & 0,78 & 0,75 & 1,00 & & & & & & & & \\
\hline $\mathrm{K}^{+}$ & 0,38 & $-0,54$ & 0,42 & 0,08 & 0,63 & $-0,52$ & $-0,69$ & 0,00 & 0,75 & 0,62 & 0,32 & 1,00 & & & & & & & \\
\hline $\mathrm{Na}^{+}$ & $-0,30$ & 0,46 & $-0,76$ & 0,32 & $-0,65$ & 0,08 & 0,50 & 0,15 & $-0,43$ & $-0,25$ & $-0,19$ & $-0,82$ & 1,00 & & & & & & \\
\hline $\mathrm{Ca}^{2+}$ & $-0,02$ & $-0,14$ & 0,27 & 0,13 & 0,13 & $-0,46$ & $-0,29$ & $-0,17$ & 0,69 & 0,69 & 0,16 & 0,79 & $-0,58$ & 1,00 & & & & & \\
\hline $\mathrm{Mg}^{2+}$ & 0,05 & 0,13 & $-0,89$ & 0,56 & $-0,32$ & $-0,21$ & 0,14 & 0,37 & $-0,17$ & $-0,04$ & 0,09 & $-0,64$ & 0,92 & $-0,58$ & 1,00 & & & & \\
\hline COT & $-0,61$ & 0,66 & $-0,39$ & 0,13 & $-0,75$ & 0,08 & 0,58 & $-0,34$ & $-0,25$ & $-0,06$ & $-0,15$ & $-0,60$ & 0,61 & $-0,04$ & 0,36 & 1,00 & & & \\
\hline CTC & 0,14 & $-0,14$ & $-0,62$ & 0,77 & $-0,08$ & $-0,79$ & $-0,28$ & 0,29 & 0,67 & 0,79 & 0,35 & 0,30 & 0,25 & 0,53 & 0,38 & 0,21 & 1,00 & & \\
\hline SB & 0,14 & $-0,14$ & $-0,62$ & 0,77 & $-0,08$ & $-0,79$ & $-0,28$ & 0,29 & 0,67 & 0,79 & 0,35 & 0,30 & 0,25 & 0,53 & 0,38 & 0,21 & 1,00 & 1,00 & \\
\hline PST & $-0,30$ & 0,47 & $-0,75$ & 0,31 & $-0,65$ & 0,09 & 0,51 & 0,14 & $-0,44$ & $-0,27$ & $-0,20$ & $-0,83$ & 1,00 & $-0,59$ & 0,92 & 0,62 & 0,23 & 0,23 & 1,00 \\
\hline
\end{tabular}

Quanto às correlações entre a argila e os atributos físicos, verificou-se correlações negativas entre a Ptcal e argila e positivas entre Ds e Rp e argila. A correlação negativa verificada entre a Porosidade total calculada (Ptcal) e a argila, deve-se à natureza das partículas de argila e suas propriedades de superfície, podendo ser resultado da gênese do solo, como também, os manejos adotados nas áreas em estudo. A porosidade total do solo refere-se à distribuição de macro e microporos, constituindo a fração do solo ocupada com ar e água, sendo uma propriedade que reflete a qualidade estrutural do solo e a fração argila contribui para maior proporção de microporo, em função do tamanho reduzido da partícula, e consequentemente, atividade coloidal alta (dependente do tipo de argila), em detrimento dos macroporos, que se manifestam na maior proporção da fração areia, sendo essa distribuição essencial para o balanço de água, ar e nutrientes adequado ao desenvolvimento das plantas (DEXTER et al., 2008).

Quanto aos sistemas de usos, vale ressaltar que as áreas de mata nativa e sob uso agroecológicos tenderam a apresentar melhor qualidade estrutural, em função dos maiores teores de COT (carbono orgânico total) que atuam na formação dos agregados, como também, a ausência de preparo intensivo do solo, ao passo que áreas sob preparo convencional devido ao tráfego de máquinas, podem ao longo do tempo, apresentar compactação da superfície e consequentemente redução do espeço poroso, como também, a migração das partículas de argila para camadas subjacentes aumenta a microporosidade e reduz a porosidade de aeração, levando a degradação dos atributos físicos (VIANA et al., 2011).

Benedetti et al., (2010) ao estudarem a resistência do solo à penetração em um latossolo vermelho distrófico típico sob diferentes usos concluíram que as diferentes formas de manejo do solo promoveram alterações na resistência do solo à penetração, concluindo que nos ambientes sob plantio convencional, integração lavoura pecuária ocorreram e pinus com pastejo obtiveram os maiores valores de resistência do solo a penetração de raízes, como também, redução na macroporosidade e elevação dos valores de densidade do solo, uma consequência direta dos sistemas de manejo adotados nestas áreas frente á área de cerrado natural, tida como referência.

Quanto às correlações positivas entre a argila e os atributos Ds e Rp podem ser justificadas pelas propriedades de superfície desta fração granulométrica, como também os sistemas de uso do solo. De modo geral, a densidade do solo e a resistência à penetração tendem a aumentar ao longo do tempo, em função da consolidação da superfície, fato verificado no estudo. As partículas de argila em função da alta área superficial específica capacidade de troca catiônica (CTC), apresenta maiores forças de adesão e coesão, propiciando a união das partículas. Quando o solo passa por preparo os agregados são rompidos independentemente do teor de umidade do solo, e as partículas mais finas e férteis (argila e matéria orgânica) são transportadas e depositadas fora do local de origem, causando o processo erosivo (BESALATPOUR et al., 2013). Esses fatores comprometem o espaço poroso, causando degradação da qualidade física do solo, interferindo em diversos atributos físicos, aumentando à densidade e a resistência à penetração após sucessivos ciclos de cultivo (STEFANOSKY et al., 2013).

No dendograma vertical obtido pela análise de agrupamentos (Figura 1A e 1B) relaciona as áreas sob diferentes usos e os atributos do solo, indicando a menor dissimilaridade e unindo as áreas semelhantes. A leitura é feita da direita para esquerda, no qual o eixo y indica as distâncias entre os grupos formados e o eixo x, representa os grupos unidos por ordem decrescente de semelhança, em que a alta dissimilaridade indica que dois indivíduos são distintos em relação ao conjunto.

Traçada a reta ao nível de $40 \%$ de dissimilaridade, a análise permitiu a formação dos grupos I e II, em função dos usos agrícolas e os atributos do solo avaliados. A análise de agrupamentos reuniu no grupo I as áreas de mata nativa (MN) e agroecológica- (A), indicando maior similaridade destas áreas entre si, quanto aos usos agrícolas e as variáveis em estudo. Isso pode ser justificado em função da mínima antropização destes ambientes, uma vez que ambientes de mata nativa não há degradação dos atributos do solo, enquanto na área agroecológica a adoção de práticas de manejo sustentáveis como a utilização de camalhoes, aliado a 
reduzida movimentação do solo contribuem para contenção do processo erosivo, culminado na melhoria e manutenção

dos atributos físicos (FIEIRA; BATISTA, 2009).

Figura 1. Dendrograma vertical, pelo método de agrupamento por ligação simples, com os grupos formados em função dos usos agrícolas (A) e variação expressiva da distância euclidiana entre as variáveis nos usos agrícolas (B).

A

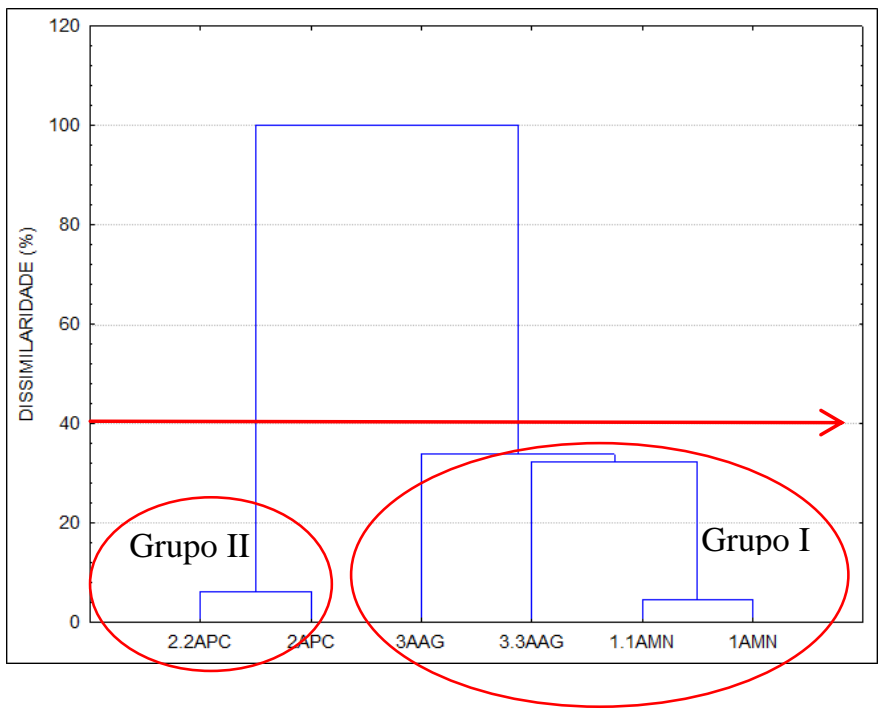

$\mathrm{Na}$ área agroecológica, é possível verificar que os atributos estruturais $\mathrm{Rp}$ e Ds e os químicos $\mathrm{COT}, \mathrm{Na}^{+}, \mathrm{K}^{+}$, PST e CE foram as que apresentaram a menor distância euclidiana. Esses resultados indicam que a realização de práticas agroecológicas de manejo do solo e dos cultivos agrícolas, mesmo em um área que vem sendo cultivada sucessivamente desde 2005 (Tabela 1), contribui para preservação dos atributos do solo comparativamente a área de mata nativa, o que evidencia a qualidade das práticas utilizadas nesse sistema, que são condizentes com a manutenção e/ou melhoria da capacidade produtiva do solo. De modo geral, o manejo agroecológico propicia melhorias nos atributos do solo, o que é um reflexo direto das melhores condições estruturais em função da adoção de práticas agroecológicas vigentes na área, como a ausência de preparo do solo e incorporação de resíduos vegetais mediante a técnica de raleamento, rebaixamento e enriquecimento da Caatinga, mantendo a biodiversidade.

A utilização do solo sob sistemas agroecológicos é eficiente do ponto vista econômico, social e ambiental na medida em que permite compatibilizar modelos sustentáveis de utilização desse recurso natural, com a demanda por alimentos, o que mantem a soberania alimentar, e causa menores impactos ambientais frente aos sistemas convencionais (NODARI et al., 2015). Cunha et al. (2014) ao estudarem os atributos solo em áreas de mata nativa e sob uso agroecológico, concluíram que o manejo agroecológico favorece a manutenção da qualidade dos atributos físicos, químicos e biológicos superando inclusive os indicadores das áreas sob mata nativa.

Neto et al., (2017) ao os atributos de um Cambissolo sob manejo sustentável da Caatinga, área de cultivo agrícola convencional e mata nativa, observaram que as práticas de manejo sustentáveis da Caatinga, como raleamento e incorporação dos resíduos, propiciaram maior qualidade do solo. Independentemente do tipo de uso, sendo que os atributos químicos matéria orgânica do solo, $\mathrm{K}+{\mathrm{e} \mathrm{Mg}^{+2}}^{+2}$
B

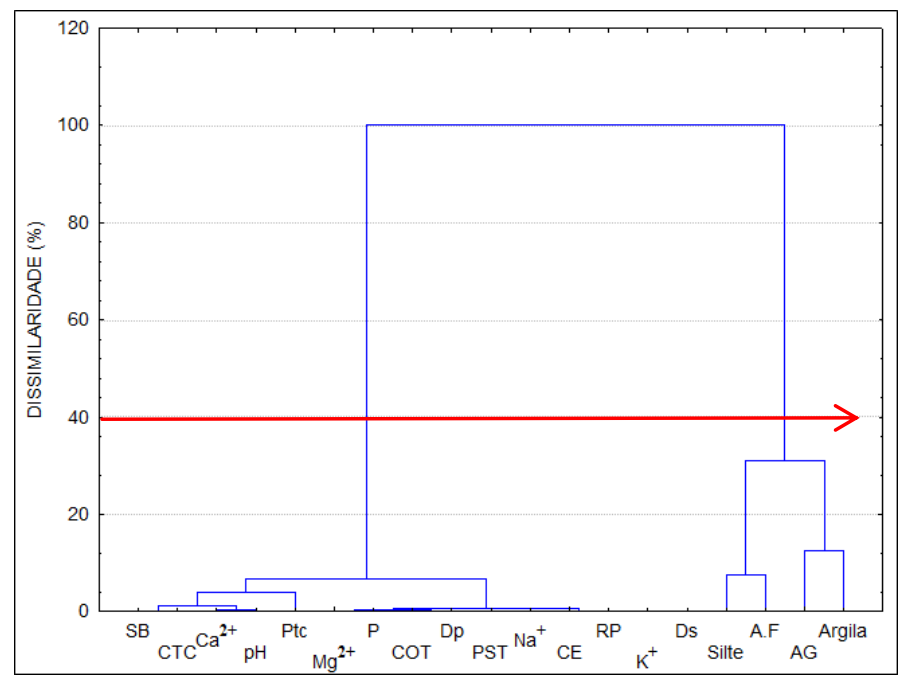

foram os indicadores mais sensíveis na alteração dos sistemas de manejo, comparação ao cultivo convencional com milho e feijão.

Quanto ao grupo II, representado pela área de plantio convencional de cultivos consorciados (PC), verificou-se o distanciamento deste agroecossistema em relação às áreas do grupo I, (Figura 2), mostrando que a ação antrópica nesse ambiente contribuiu para a diferenciação dos seus atributos quanto à agroecossistemas conservados, como a área de mata nativa, que tem a mínima perturbação antrópica, assim como, no manejo agroecológico. Possivelmente, essa diferenciação ocorreu em função da adoção de práticas de movimentação do solo, como aração e gradagem no plantio convencional, que promovem o rompimento dos agregados e compromete a estrutura do solo, reduzindo os teores de COT pela exposição direta da matéria orgânica e revolvimento para as camadas subjacentes, levando a degradação dos atributos estruturais.

Mazaranna et al., (2011) constataram os efeitos do preparo do solo ao estudar as alterações na sua estrutura e rendimento das culturas, concluindo que os sistemas com preparo do solo com maior grau de mobilização ao longo do tempo comprometeram a densidade, porosidade, resistência mecânica à penetração e infiltração de água, causando a redução da produtividade agrícola.

Na Tabela 3 está apresentada a análise fatorial, contendo os fatores extraídos das 19 variáveis estudadas, sendo que a proporção acumulada do Fator $1(\mathrm{~F} 1)$ ao 4 (F4) foi de 97,20\% da variabilidade total dos resultados obtidos.

No F1, destacaram-se as variáveis: $\mathrm{Dp}, \mathrm{pH}, \mathrm{CE}$, $\mathrm{Ca}^{+2}$, CTC e $\mathrm{SB}$, enquanto o $\mathrm{F} 2$ prevaleceram as variáveis areia fina (AF), $\mathrm{K}^{+}, \mathrm{Na}^{+}, \mathrm{Mg}^{+2}$ e PST. Esses resultados podem ser justificados pela litologia da classe Cambissolo, sob a formação geológica Cálcário Jandaíra, uma vez que os assentados não utilizam fertilizantes minerais nas áreas cultivadas desde 2005 (Tabela 1). 
Tabela 3. Coeficiente de correlação dos componentes principais (Fatores 1, 2, 3 e 4) para os atributos físicos e químicos do solo, em função dos sistemas de uso e manejo do solo, nas camadas de 0-5 e 5-10 cm. Coeficientes de correlação > $|0,70|$ são significativos.

\begin{tabular}{ccccc}
\hline Atributos & \multicolumn{4}{c}{ Fatores } \\
\hline Argila & 0,12 & 0,02 & 0,95 & $-0,26$ \\
AG & $-0,16$ & 0,16 & $-0,94$ & 0,24 \\
A.F & $-0,43$ & $-0,87$ & $-0,24$ & $-0,05$ \\
Silte & 0,68 & 0,50 & 0,54 & 0,06 \\
Ds & $-0,02$ & $-0,40$ & 0,89 & $-0,14$ \\
Dp & $-0,79$ & $-0,04$ & $-0,54$ & $-0,13$ \\
Ptcalc & $-0,33$ & 0,28 & $-0,87$ & 0,04 \\
RP & 0,18 & 0,42 & 0,72 & $-0,49$ \\
pH & 0,76 & $-0,28$ & 0,58 & 0,03 \\
CE & 0,86 & $-0,13$ & 0,47 & 0,09 \\
P & 0,36 & 0,07 & 0,89 & 0,27 \\
$\mathrm{~K}^{+}$ & 0,48 & $-0,78$ & 0,31 & $-0,21$ \\
Na $^{+}$ & 0,03 & 0,94 & $-0,31$ & 0,06 \\
Ca $^{2+}$ & 0,72 & $-0,66$ & $-0,09$ & 0,07 \\
Mg $^{2+}$ & 0,13 & 0,96 & 0,02 & $-0,06$ \\
COT & 0,17 & 0,45 & $-0,50$ & 0,69 \\
CTC & 0,97 & 0,24 & 0,01 & $-0,07$ \\
SB & 0,97 & 0,24 & 0,01 & $-0,07$ \\
PST $_{\text {Autovalores }}$ & 0,01 & 0,94 & $-0,32$ & 0,06 \\
\hline Variância Total $(\%)$ & 8,86 & 5,85 & 3,01 & 0,75 \\
Variância Acumulada $(\%)$ & 46,62 & 30,77 & 15,84 & 3,97 \\
\hline & & & &
\end{tabular}

Figura 2. Distribuição da nuvem de variáveis, no círculo de correlações (A) e distribuição da nuvem de pontos representando a relação entre fatores 1 e 2 sob diferentes usos (B).

\section{A}

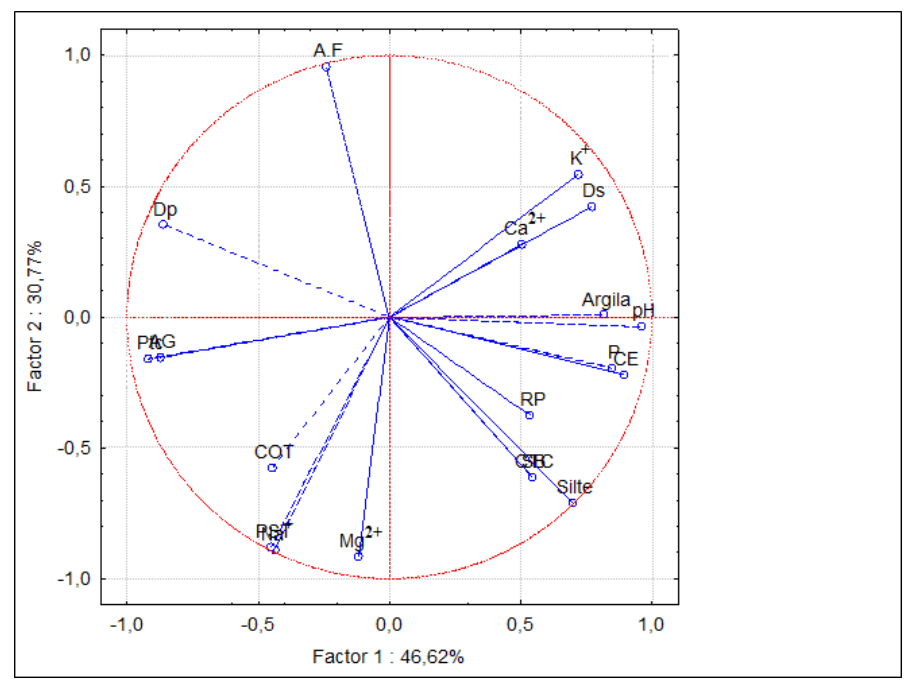

Desta foram, o círculo de correlação (Figura 3A e B) os usos agrícolas sob mata nativa $(\mathrm{MN})$ e área agroecológica $(\mathrm{Ag})$ se posicionam no mesmo plano do gráfico, destacandose as variáveis físicas e químicas, COT, $\mathrm{Na}^{+} \mathrm{Mg}^{+2}$ e PST, Ptcalc, areia grossa e DP, retratando as inter-relações existentes entre esses atributos e os usos agrícolas. A similaridade para estes atributos pode estar associada à
O calcário Jandaíra é composto por rochas básicas ricas em carbonatos, fornecendo $\mathrm{Ca}^{+2}, \mathrm{Mg}^{+2}, \mathrm{Na}^{+}$e $\mathrm{K}^{+}$em proporções variáveis, contribuindo para a alta fertilidade natural encontrada no estudo. Além disso, de acordo com Ronquim, (2010) a área sob o calcário jandaíra é texturalmente mais argilosa, com a textura predominantemente composta de argilas de atividade alta, como a ilita (2:1), mica (2:1) e vermiculita (2:1), com predominância das bases divalentes $\mathrm{Ca}^{+2}$ e $\mathrm{Mg}^{+2}$, que exibem alta área superficial específica, incidindo diretamente sobre os maiores valores de CTC encontrados assim como explica a predominância destes íons divalentes no complexo de troca.

Melo et al., (2017) ao realizar a caracterização de solos sob esta formação geológica corrobora esta pesquisa, verificando altos valores de SB constatando que praticamente toda a CTC do solo estava ocupada por cátions essenciais $\left(\mathrm{Ca}^{2+}, \mathrm{Mg}^{2+}\right.$ e $\left.\mathrm{K}^{+}\right)$. Moreira et al., (2007) ao realizar caracterização química e física dos solos na região da Chapada do Apodi-RN chegaram a resultados semelhantes, constatando os efeitos da litologia da região sobre os índices de fertilidade.

Quantos aos demais fatores (F3e F4), apenas o F3 obteve cargas fatoriais expressivas para a diferenciação dos ambientes, destacando-se os atributos físicos argila, areia grossa, Ds e porosidade total calculada, além do fósforo, corroborando os resultados encontrados na matriz de correlação (Tabela 1).

A partir da relação entre esses componentes, realizou-se a ordenação bidimensional e os diagramas de projeção de vetores, sendo que a visualização dos diagramas permitiu analisar quais atributos mais distinguiram as áreas sob sistemas de manejo e usos agrícolas (Figura 2A e 2B). 
e mantendo o arranjo estrutural do solo, refletindo na porosidade total, melhorando a entrada de água, ar e nutriente (OLIVEIRA et al., 2016).

Resende et al., (2012) ao avaliarem as características física do solo sob diferentes usos, concluíram que área com deposição de resíduos apresentavam maiores estoques de MOS, refletindo em melhores condições estruturais do solo quanto aos atributos físicos: macroporosidade, densidade e porosidade total, constatando que a conversão das área de mata nativa em áreas agrícolas reduziu os estoques de MOS e consequentemente, causou a perda de qualidade física. $\mathrm{O}$ estoque de MOS é mantido e/ou aumentado em ambientes que apresentam biodiversidade de plantas, como também preparo mínimo do solo, sendo que esta se destaca no fornecimento de nutrientes por meio da mineralização de suas fações húmicas, sendo uma das principais responsáveis pela CTC do solo sob a forma humificada, sobretudo em solos intemperizados, funcionando como uma fonte de liberação lenta de nutrientes para as plantas, sob sistemas de usos agrícolas onde não há entrada de nutrientes de fontes externas, constituindo-se na principal fonte de fornecimento e reposição de nutrientes exportados pelas culturas (PRIMO; SILVA, 2011).

Souza et al. (2015) ao estudarem os atributos do solo em usos agrícolas na região de Governador Dix Sept Rosado, encontrou quantidades representativas de COT em área de mata nativa para um ambiente de condições semiáridas, como também, cálcio e magnésio, constatando que a fertilidade dessas áreas é consequência da litologia local (Calcário Jandaíra) e da deposição de matéria orgânica.

Quantos aos fatores F3e F4 observa-se que apenas o F3 obteve cargas fatoriais expressivas para a diferenciação dos ambientes, destacando-se os atributos físicos argila, areia grossa, Ds e porosidade total calculada e químicos, tal como o fósforo, corroborando os resultados encontrados na matriz de correlação (Tabela1, Tabela 3 e Figuras 3A e 3B).

Figura 3. Distribuição da nuvem de variáveis, no círculo de correlações (A) e distribuição da nuvem de pontos representando a relação entre fatores 3 e 4 sob diferentes usos (B).

A

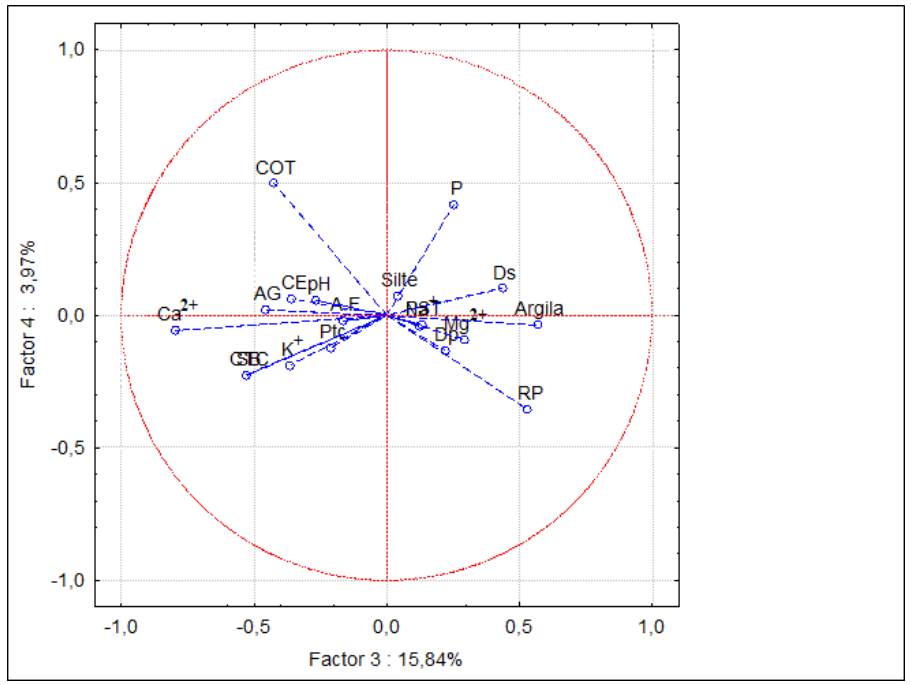

A sobreposição dos planos fatorias (Figura 3A e B) permite identificar que estas variáveis distinguem os ambientes agroecológico $(\mathrm{Ag})$ da área de plantio convencional de cultivos consorciados (PC) e mata nativa (MN) sendo a densidade do solo e a resistência á penetração de raízes as mais sensíveis, o que indica a melhoria destes atributos físicos em função do manejo adotado na $\mathrm{Ag}$ com práticas conservacionistas, em relação á $\mathrm{PC}$, confirmando o resultado encontrado no dendograma vertical, conforme verificado nas Figuras $2 \mathrm{~A}$ e $2 \mathrm{~B}$.

\section{CONCLUSÕES}

As áreas de mata nativa e agroecológica apresentam maior similaridade, em relação à área de plantio convencional de cultivos consorciados, destacando-se os atributos: porosidade total, resistência à penetração de raízes, densidade do solo, carbono orgânico total e fósforo, o que indica melhoria dos atributos estruturais em função das práticas agroecológicas adotadas.
B

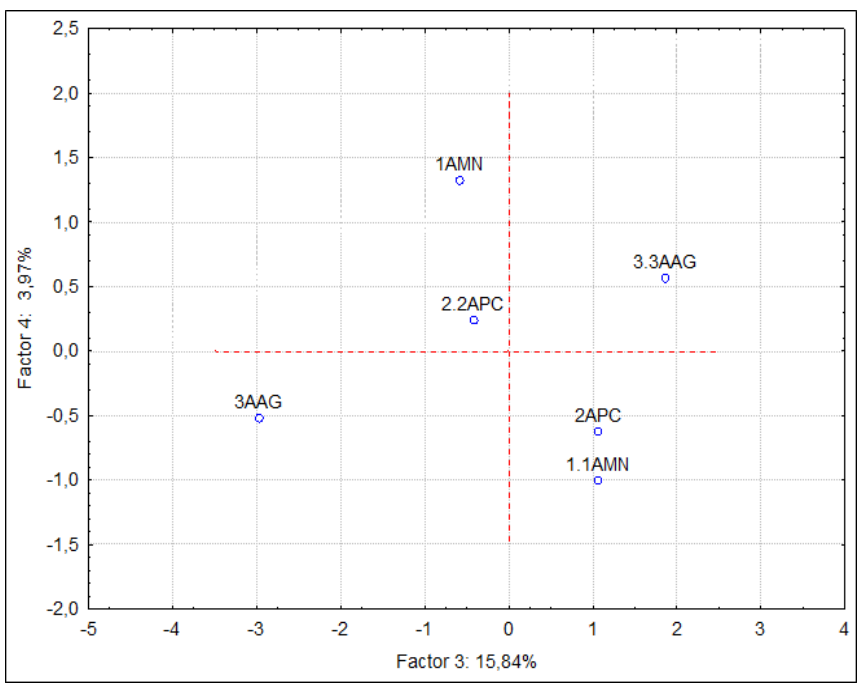

A técnica da análise multivariada permite diferenciação das áreas, destacando-se os atributos físicos e químicos influenciados pelos manejos do solo e dos cultivos agrícolas.

\section{REFERÊNCIAS}

ALVARES, C. A.; STAPE, J. L.; SENTELHAS, P. C.; GONÇALVES, J. L. M. de.; SPAROVEK, G. Koppen's climate classification map for Brazil. Meteorologische Zeitschrift, v.22, n. 6, p. 711-728, 2013.

ARRUDA, L. E. V.; PORTELA, J. C.; MEDEIROS, J. F. ; BATISTA, R. O.; MELO, S. B. ; SOUZA, C. M. M.; LOPES, T. C. S.; MENDES, K. R. Chemical Attributes of an Oxisol Under Different Agricultural Uses in the Brazilian Semiarid Region. Journal of Agricultural Science, v.10, p.501, 2018.

BENEDETTI, M. M., DUARTE, I. N.,MELO JÚNIOR, H. B.; BORGES, E. N. Resistência do solo à penetração em um Latossolo Vermelho distrófico típico sob diferentes usos. Enciclopédia Biosfera, v. 6, p. 1-9, 2010. 
BERTOL, I.;VASQUEZ, E. V.; GONZÁLEZ, A. P.; COGO, N. P.; LUCIANO, R. V.; FABIAN, E. L. Sedimentos transportados pela enxurrada em eventos de erosão hídrica em um Nitossolo Háplico. Revista Brasileira de Ciência do Solo, Campinas. v. 34, n. 1, p. 245-252.

BESAlATPOUR, A. A., AYOUBI, S., HAJABBASI, M. A., MOSADDEGHI, M., \& Schulin, R. Estimating wet soil aggregate stability from easily available properties in a highly mountainous watershed. Catena, v. 111, p. 72-79, 2013.

CASALI, VICENTE W. D.; ANDRADE, FERNANDA M. C.; CUPERTINO, M. C. Homeopatia, Agroecologia e Sustentabilidade. Revista Brasileira de Agroecologia, v. 6, n. 1, Junho, 2011.

CONCEIÇÃO, P. C., BAYER, C., DIEKOW, J \& SANTOS, D. C. D. Fracionamento físico da matéria orgânica e índice de manejo de carbono de um Argissolo submetido a sistemas conservacionistas de manejo. Ciência rural. Santa Maria. v. 44, n. 5, p. 794-800., 2014.

CUNHA, J. A. D. S., BARROS, R. F. M., MHEL, H. U., \& SILVA, P. R. R. Atributos agroecológicos de solo e caracterização de predadores generalistas no cultivo de melancia nos tabuleiros litorâneos do Piauí, Brasil. Revista Brasileira de Agroecologia, v. 9, n. 1, p. 269-281, 2014.

DEXTER, A. R., RICHARD, G., ARROUAYS, D., CZYŻ, E. A., JOLIVET, C.; DUVAL, O. Complexed organic matter controls soil physical properties. Geoderma, v. 144, n. 3-4, p. 620-627, 2008.

FORSYTHE, W. Fisica de suelos: Manual de laboratório San José, Costa Rica: IICA, 1975. 212p. EMBRAPA, Centro Nacional de Pesquisa de Solos, Rio de Janeiro, RJ. 2. Ed. Rio de Janeiro: 1997. 212p.

HAIR, J. F., BLACK, W. C., BABIN, B. J., ANDERSON, R. E., \& TATHAM, R. L.Análise multivariada de dados. Bookman Editora, 2009.

FREITAS, L., OLIVEIRA, I. A., SILVA, L. S., FRARE, J. C V., FILLA, V. A., GOMES, R. P. Indicadores da qualidade química e física do solo sob diferentes sistemas de manejo. Revista Unimar Ciências, v. 26, n. 1-2, 2017.

KIEHL, E. J. Manual de Edafologia: relação solo-planta. Piracicaba: Ceres, 1979. 262p.

LIRA, R. B., Da SILVA DIAS, N., ALVES, S. M., DE BRITO, R. F., SOUSA NETO, O. N. Efeitos dos sistemas de cultivo e manejo da caatinga através da análise dos indicadores químicos de qualidade do solo na produção agrícola em Apodi, RN. Revista Caatinga, v. 25, n. 3, p. 18$24,2012$.

MAZURANA, M., LEVIEN, R., MÜLLER, J., CONTE, O. Sistemas de preparo de solo: alterações na estrutura do solo e rendimento das culturas. Revista brasileira de ciência do solo. Campinas. v. 35, n. 4 p. 1197-1206, 2011.
MELÉM JUNIOR, N. J.; FONSECA, I. C. B.; BRITO, O .R.; DECAËNS, T.; CARNEIRO, M. M.; MATOS, M. F. A.; GUEDES, M. C.; QUEIROZ, J. A. L., BARROSO, K.O. Análise de componentes principais para avaliação de resultados analíticos da fertilidade de solos do Amapá. Semina, v. 29, p.499-506, 2008.

MELO, A. F. D., DE SOUZA, C. M. M., Da SILVA REGO, L. G., DA SILVA LIMA, R. N., MOURA, I. N. B. M. Pedogênese de chernossolos derivados de diferentes materiais de origem no oeste potiguar. Agropecuária científica no semiárido, v. 13, n. 3, p. 229-235, 2017.

MOREIRA, J. N., COSTA De MORAIS, E. R., MAIA, C. E., GURGEL FERNANDES, J. (2007). Caracterização química e física dos solos do assentamento de reforma agrária MAISA em Mossoró, RN. Revista de Biologia e Ciências da terra, v. 7, n. 2, 2007.

NETO, J. M. Estatística multivariada: uma visão didáticametodológica. , 2015

NODARI, R. O; GUERRA, M. P. A agroecologia: estratégias de pesquisa e valores. Estudos avançados, v. 29, n. 83, p. 183$207,2015$.

OLIVEIRA, E. C. A. M., PELUZIO, J. M., de OLIVEIRA JUNIOR, W. P., TSAI, S. M., NAVARRETE, A. A.; de MORAIS, P. B. Alterações dos atributos físico-químicos da camada superficial do solo em resposta à agricultura com soja na várzea do Tocantins. Biota Amazônia Biote Amazonie, Biota Amazonia, Amazonian Biota, v. , 5, p. 56-62, 2015.

OLIVEIRA, J. G. R; FILHO, J .T; BARBOS, G. M. C. Alterações na física do solo com a aplicação de dejetos animais. Geographia Opportuno Tempore, v. 2, n. 2, p. 66-80, 2016.

PORTUGAL, A. F; COSTA, D. V. O; COSTA, L. M. Propriedades físicas e químicas do solo em áreas com sistemas produtivos e mata na região da Zona da Mata mineira. Revista Brasileira de ciência do solo, v. 34, n. 2, 2010.

PRIMO, D. C., MENEZES, R. C.; SILVA, T. O. Substâncias húmicas da matéria orgânica do solo: uma revisão de técnicas analíticas e estudos no nordeste brasileiro. Scientia Plena, v. 7, n. 5, 2011.

RESENDE, T. M., DE MORAES, E. R., FRANCO, F. O., ARRUDA, E. M., ARAÚJO, J. R., DA SILVA SANTOS, D.; RIBEIRO, B. T.. Avaliação física do solo em áreas sob diferentes usos com adição de dejetos animais no bioma cerrado. Bioscience Journal, v. 28, n. 1, 2012.

RIBEIRO, A. C., GUIMARÃES, P. T. G., VENEGAS, V. H. A. Recomendação para o uso de corretivos e fertilizantes em Minas Gerais (5th ed., p. 359). Viçosa: Comissão de Fertilidade do Solo do Estado de Minas Gerais. 1999. 
RONQUIM, C. C. Conceitos de fertilidade do solo e manejo adequado para as regiões tropicais - Campinas: Embrapa Monitoramento por Satélite, 26 p, 2010.

SANTOS, R. D.; LEMOS, R. C.; SANTOS, H. G.; KER, J. C.; ANJOS, L. H. C. dos; SHIMIZU, S. H. Manual de descrição e coleta de solos no campo. 6.ed. Viçosa: Sociedade Brasileira de Ciência do Solo, 100p, 2013.

SOUSA NETO, O. N. D., DIAS, N. D. S., LIRA, R. B. D., SILVA, E. F. D., FERREIRA, A. L.; FREITAS, J. J. Chemical attributes of traditional agriculture and Caatinga managed at different depths in an Inceptisol. Revista Brasileira de Engenharia Agrícola e Ambiental, v. 21, n. 1, p. 50-55, 2017.

SOUZA, R. O.; PORTELA, J. C., MARTINS, C. M., DIAS, N. S., CAVAlCANTE, J. S. J., SILVA, J. F. SÁ, F. V. S. Soil attributes in agricultural uses and in the Semiarid RN-
Brazil in eutrophic Cambisol. African Journal of Agricultural Research, v. 10, n. 37, p. 3636-3643, 2015.

Stasoft. Statistica Version 7.0. StatSoft. Retrieved from: http://www.statsoft.com. 2004.

STEFANOSKI, D. C., SANTOS, G. G., MARCHÃO, R. L., PETTER, F. A., PACHECO, L. P. Uso e manejo do solo e seus impactos sobre a qualidade física. Revista Brasileira de Engenharia Agrícola e Ambiental, v. 17, n. 12, 2013.

TEIXEIRA, P. C.; DONAGEMMA G. K.; WENCESLAU, A. F.; TEIXEIRA, G. Manual de Métodos de Análise de Solo. 3. ed. Rio de Janeiro: Embrapa Solos, 573 p. 2017.

VIANA, E. T, BATISTA, M. A., TORMENA, C. A., COSTA, A. C. S, INOUE, T. T. Atributos físicos e carbono orgânico em Latossolo Vermelho sob diferentes sistemas de uso e manejo. Revista Brasileira de Ciência do Solo, v. 35, n. 6, 2011. 